\title{
Víctor Lara Bermejo \\ Los clíticos de segunda persona de plural en las lenguas romances de la Península Ibérica
}

https://doi.org/10.1515/zrp-2018-0003

\begin{abstract}
The Romance languages of the Iberian Peninsula possess a second person plural subject pronoun that induces verb and pronoun agreement in $2 \mathrm{pl}$. While standard Catalan chooses us/vos as unstressed pronouns, Portuguese selects vos and Spanish, os. Nevertheless, the data taken from linguistic atlases of the 20th century point out the great quantity of $2 \mathrm{pl}$ allomorphs in unstressed pronouns: tos, sos, sus, los and se. In this article, I aim to account for the linguistic geography of $2 \mathrm{pl}$ allomorphs and their possible linguistic factors.
\end{abstract}

Keywords: clitics, allomorphs, Iberoromance, linguistic geography, dialectology

Palabras clave: clíticos, alomorfos, iberorromance, geografía lingüística, dialectología

\section{Introducción}

La segunda persona del plural (2pl) en las lenguas romances de la Península Ibérica ha sufrido varias transformaciones a lo largo de la historia. A diferencia de otras lenguas romances, que han sabido conservar mejor la herencia del vos latino, el portugués, el catalán y el español (así como sus variedades) disponen de varias estrategias para expresar la 2pl, las cuales se complican todavía más en la elección del clítico o pronombre átono. En principio, los tres idiomas disponen de un sistema bimembre de pronombres según la cortesía. En la informalidad, vosotros, vosaltres más 2pl se atestiguan en español y catalán, mientras que el portugués prefiere vocês más 3pl. Para la formalidad, las tres lenguas recurren a la 3pl más las formas ustedes, vostès, vocês / os senhores. Sin embargo, el español y el portugués peninsulares ofrecen dos variedades diversas a este respecto. En el primer caso, encontramos la situación del andaluz occidental, donde vosotros ha

Dirección de correspondencia: Dr. Víctor Lara Bermejo, Universität Bern, Institut für spanische Sprachen und Literaturen, Länggassstrasse 49, Postfach, CH-3009 Bern, E-Mail:viktoresc@hotmail.com 
desaparecido y ustedes es el único pronombre de 2pl (Lara 2012). Sin embargo, sus concordancias alternan entre morfología de $2 \mathrm{pl} \mathrm{y} 3 \mathrm{pl}$. En el caso del portugués, hallamos dos áreas geográficas, una en el centro-norte y otra, en el centrosur. La primera exhibe un sistema arcaico de tratamientos, puesto que posee vós más $2 \mathrm{pl}$ para la informalidad y vocês más 3pl para la formalidad, mientras que la segunda sigue el patrón descrito más arriba, donde vós ya no existe y la concordancia es de 3pl (Cunha/Cintra 1992; Brito et al. 2006).

Acabamos de puntualizar que el andaluz occidental induce concordancias de $2 \mathrm{pl}$ y $3 \mathrm{pl}$ (tanto en verbos como en clíticos), pero el caso del portugués es levemente más complejo. En la zona centro-norte, el tratamiento vós siempre se concuerda con 2pl (los clíticos se corresponden con la forma átona vos), pero, en la zona sur, vocês tiene concordancia de 3pl en el reflexivo y el verbo, mientras que los clíticos de objeto son de 2pl (vos). En el español peninsular (excepto en Andalucía occidental), los clíticos de 2pl se corresponden en la variedad estándar con os y en catalán podemos hallar vos como forma proclítica y us como alternativa enclítica (Wheeler/Yates/Dols 1999).

Las monografías dialectales aluden al hecho de que los clíticos de 2pl no solo recaen en os o vos / us, sino que existe una variedad de alomorfos que incluye las formas estándares y otras vernáculas, como los, tos, sos, sus e incluso se. Este artículo pretende, por tanto, estudiar dicha variedad dialectal a lo largo del siglo XX, desde un punto de vista geolingüístico y tipológico.

\section{Corpus y metodología}

Con el fin de cartografiar la distribución dialectal de los alomorfos de 2pl a lo largo del siglo pasado, hemos optado por extraer los datos de los distintos atlas lingüísticos que se llevaron a cabo en la centuria de 1900. Empezaremos por el Atlas lingüístico de la Península Ibérica (ALPI) y terminaremos por los distintos trabajos regionales de segunda mitad de siglo: ALEC-MAN, ALEANR, ALEA, ALECANT. Por último, compararemos los datos con los que proporciona el corpus dialectal COSER, cuyas muestras vernáculas datan de 1990 hasta la fecha.

El Atlas lingüístico de la Península Ibérica (ALPI) data de mediados del siglo $\mathrm{XX}$ y está compuesto por dos cuadernos de encuesta, donde se muestra una serie de palabras y oraciones pensadas ad hoc, que el informante (una persona mayor, iletrada y procedente de un ámbito rural) debía repetir. Con ellas se pretendía dar cuenta de la variación léxica, morfosintáctica y fonética de las lenguas romances en todo el territorio peninsular (Sanchís Guarner et al. 1962). Para observar las variaciones pronominales clíticas de la segunda persona del plural en el ALPI, hemos utilizado las siguientes preguntas: 341. Os vais a caer; 342. Os han engañado; 
343. ¿Os queréis callar?; 344. Arrodillaos y 345. Bebeos este vaso de aguardiente (ALPI).

En el caso de los demás atlas lingüísticos, estos se llevaron a cabo con una metodología similar a la del ALPI y, en muchas ocasiones, con oraciones preestablecidas idénticas a este. Aunque el análisis sintáctico es el que menos se favorece con dicha metodología, sigue resultando útil para nuestros fines. El modus operandi del COSER, no obstante, difiere en gran medida. Su obtención de ocurrencias se basa en la entrevista semidirigida sobre temas del mundo rural con informantes de ambos sexos, iletrados y de entorno rural, sin apenas movilidad y con una edad a partir de los 55. La espontaneidad de la conversación garantiza el no condicionamiento del discurso del entrevistado, quien, gracias a la misma, suele producir mayor cantidad de ejemplos de un mismo fenómeno lingüístico, engrosando, por tanto, de manera cuantitativa y cualitativa el corpus (Fernández-Ordóñez 2010, 123s.).

\section{Descripción de los resultados}

A continuación, expondremos los mapas de 2pl a partir de los datos del ALPI.

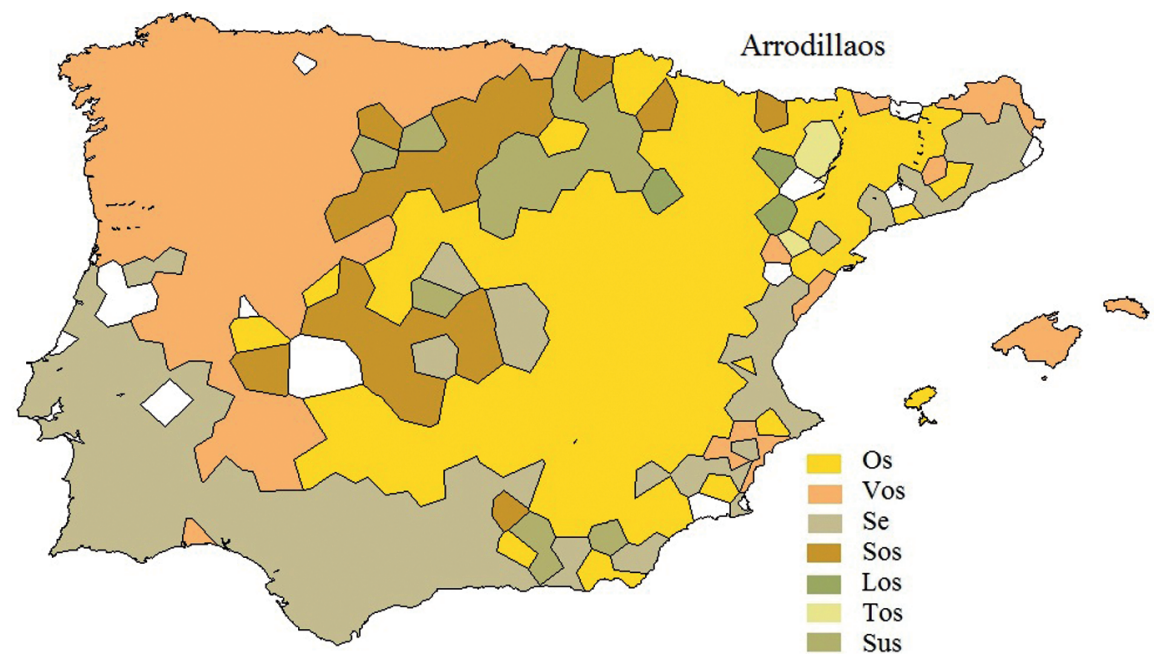

Mapa 1: Morfología en imperativo (reflexivo).

La pregunta con un imperativo ha dado como resultado siete variantes distintas de pronombre átono con referencia 2pl. Existen tres opciones mayoritaria: vos, en el occidente peninsular (y Baleares); os, en el centro-oriente (us en zona catalana), y se 
en el centro-sur portugués, Andalucía y gran parte de la zona valenciana y en Cataluña oriental. De manera más minoritaria hallamos las soluciones sos, sus, tos y los.

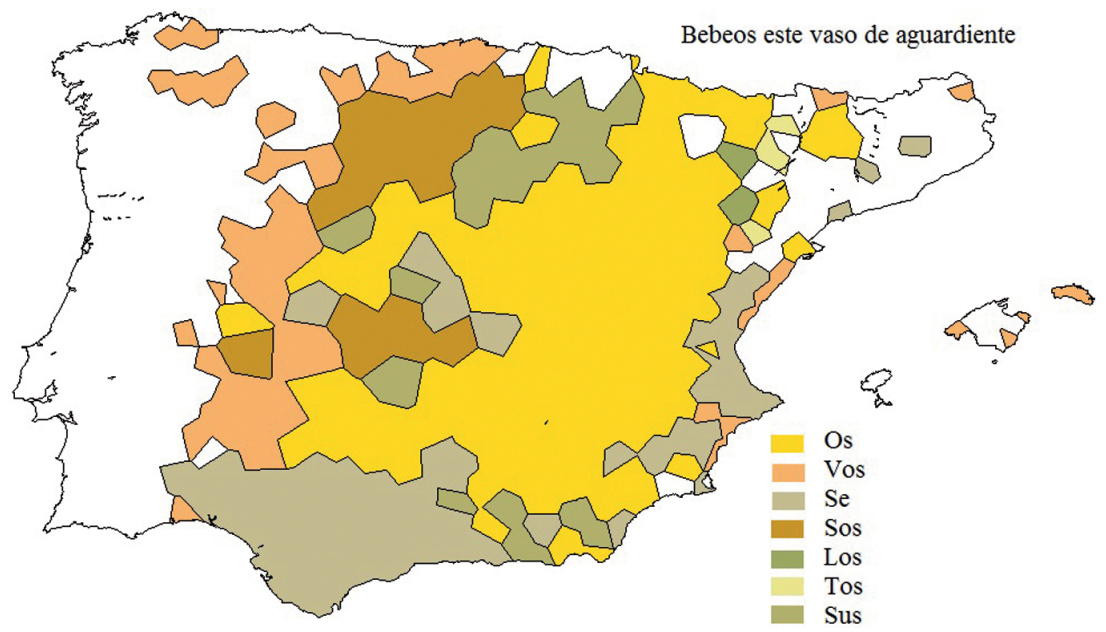

Mapa 2: Morfología en imperativo (dativo ético).

En este caso, aunque estamos ante un imperativo, el pronombre tiene función de dativo ético. En primer lugar, ese dativo es inexistente en portugués y gran parte de Cataluña y Baleares. De nuevo, las respuestas mayoritarias corresponden a os, vos y se. En menor medida están sos, sus, tos y los.

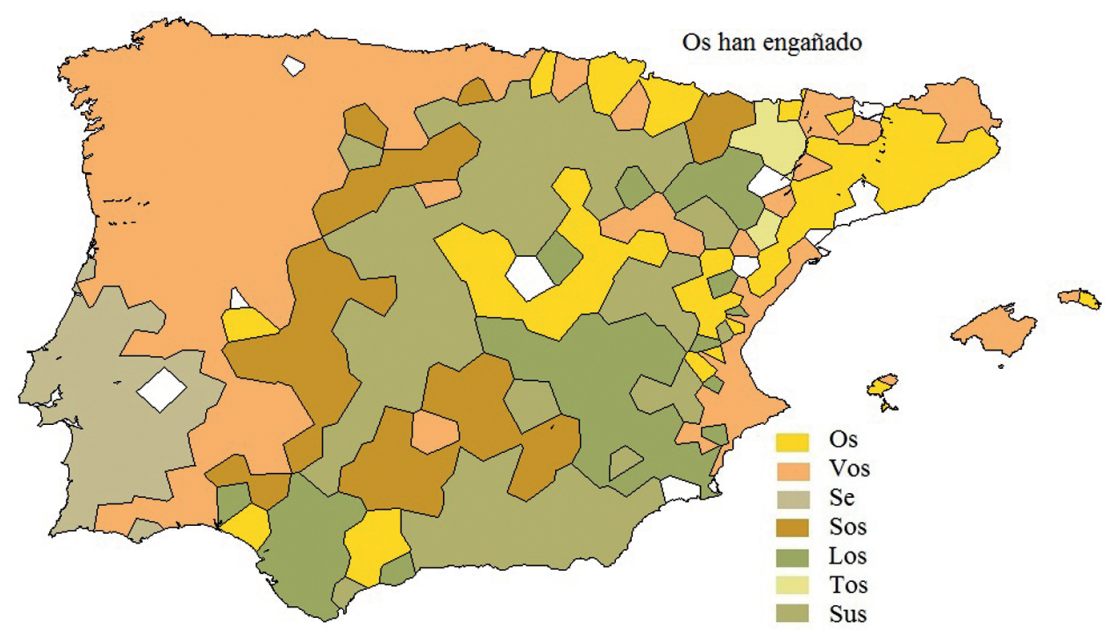

Mapa 3: Morfología acusativo. 
La pregunta referida a un pronombre en función de objeto directo modifica de algún modo los resultados. Otra vez, vos se extiende por el oeste peninsular (aunque cubre un espacio más amplio) y el catalán. El uso estándar de os decrece exponencialmente y se concentra en área catalana (us) y enclaves del centro y sur peninsulares. Las formas sus y sos se revelan hegemónicas en el centro de España frente al uso de la $3 \mathrm{pl}$ (os) en una pequeña parte del suroeste de Portugal, una zona pirenaica que prefiere tos y una gran área oriental y andaluza que ha optado por los.

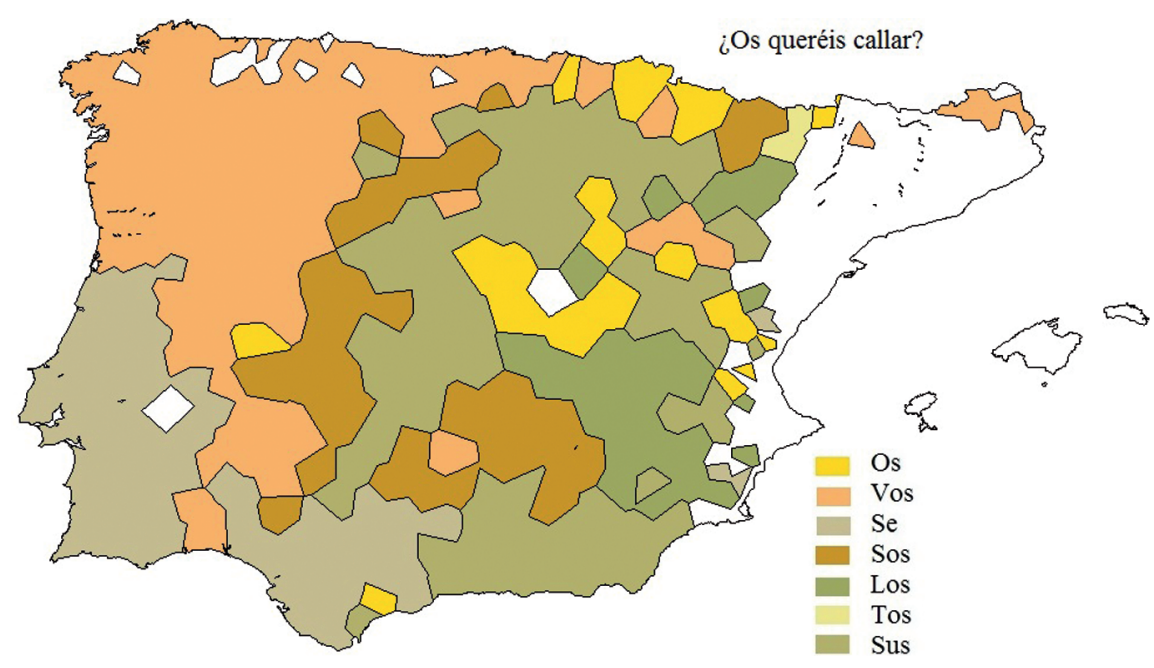

Mapa 4: Morfología reflexivo antepuesto (I).

De nuevo, este mapa nos muestra el comportamiento del reflexivo, aunque en posición preverbal. El uso de vos es coherente, mientras que sos / sus decrece levemente y el empleo estándar de os es minoritario. Tos se mantiene en el norte de Aragón, mientras los permanece en el oriente peninsular. Por último, el catalán no muestra forma reflexiva con el verbo calar y el portugués meridional y el andaluz occidental han optado por se.

Por último, el mapa 5 ilustra el comportamiento del reflexivo antepuesto. Frente a la carencia de reflexivo en portugués y catalán, el español ofrece las mismas alternativas, cuya difusión se repite de forma consistente.

Describamos ahora la geografía de estos alomorfos en los atlas de segunda mitad del siglo XX. Empecemos por el ALEC-MAN. 


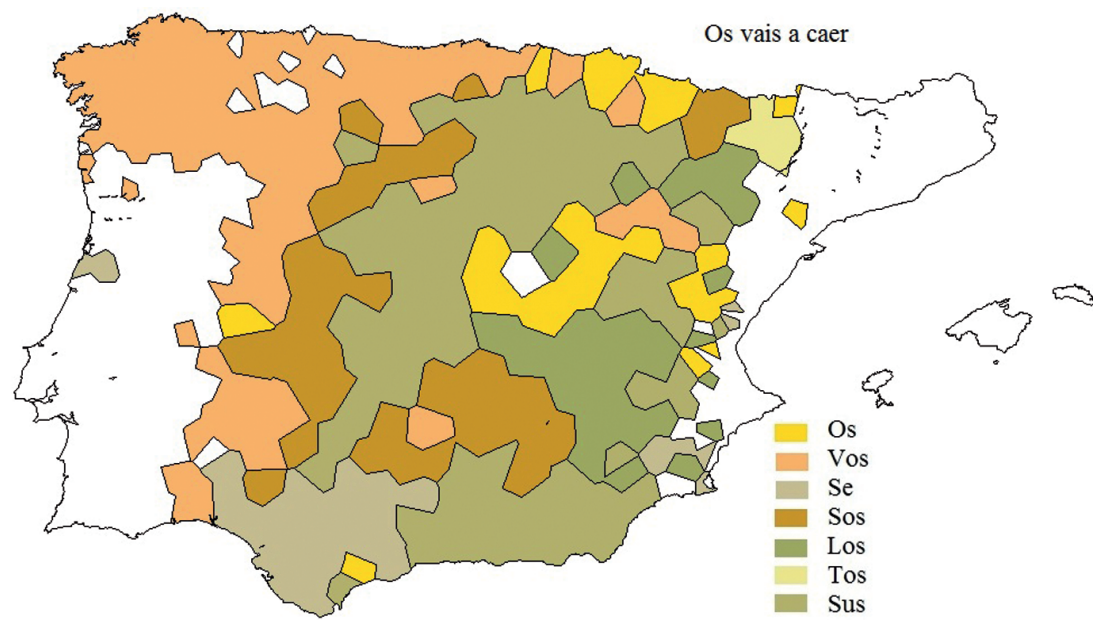

Mapa 5: Morfología reflexivo antepuesto (II).

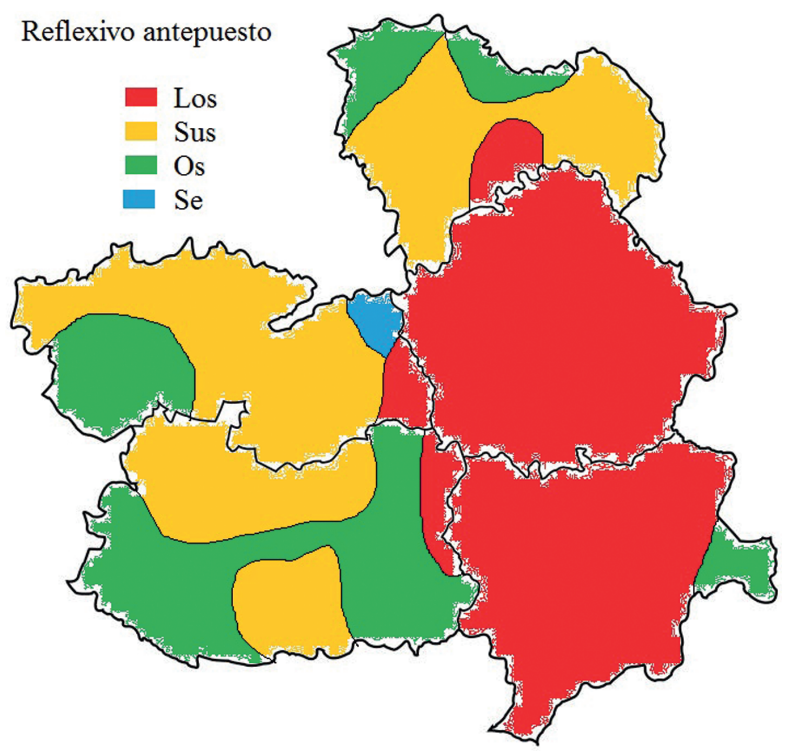

Mapa 6: Morfología reflexivo antepuesto (III).

El mapa 6 muestra un reflexivo antepuesto (os reís), siendo la opción de los la mayoritaria en el oriente y sus, en el resto, si bien es cierto que el estándar os se distribuye ampliamente. Solo en una zona muy acotada observamos el empleo de se (se reís). 


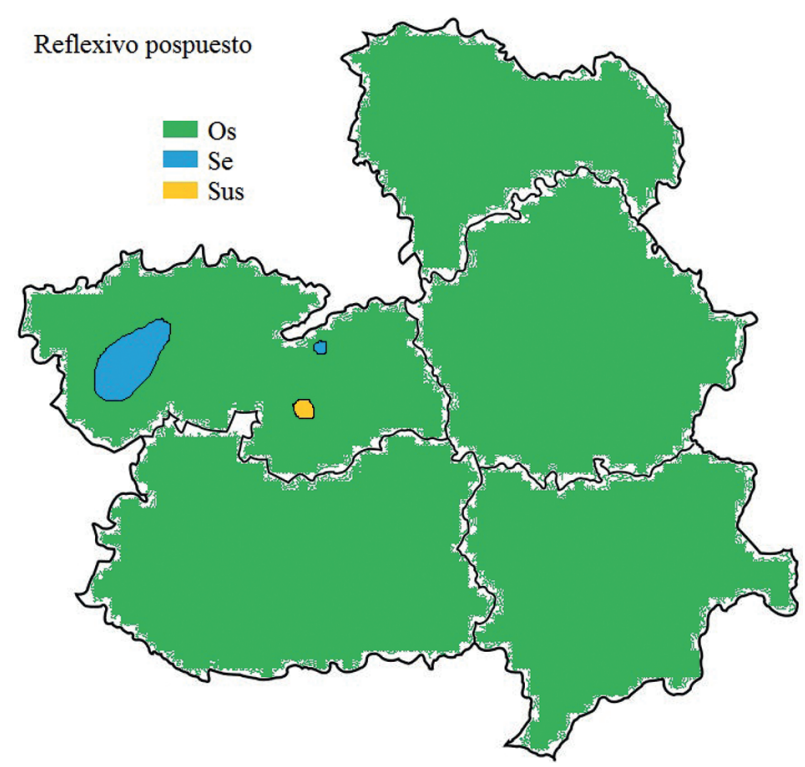

Mapa 7: Morfología del reflexivo pospuesto (I).

El mapa 7 ilustra la función sintáctica reflexiva, aunque esta vez pospuesta (arrodillaos). Su expresión, al estar influida por un imperativo que se ha producido en forma de infinitivo (arrodillar) ha provocado una elección hegemónica de os, un solo enclave con sus y un par de áreas donde se ha optado por se.

El mapa 8, en este caso, ofrece un pronombre en función de dativo (os dieron dinero) y, aunque la zona de los sea, prácticamente, la misma, las ocurrencias del estándar os aumentan en detrimento del vernáculo sus. Interesante, sin embargo, resulta la producción de se como dativo (se dieron dinero [a vosotros]), como una extensión de dicha forma a cualquier contexto sintáctico, sin que se caracterice únicamente por su reflexividad. Observemos ahora el ALEA. 


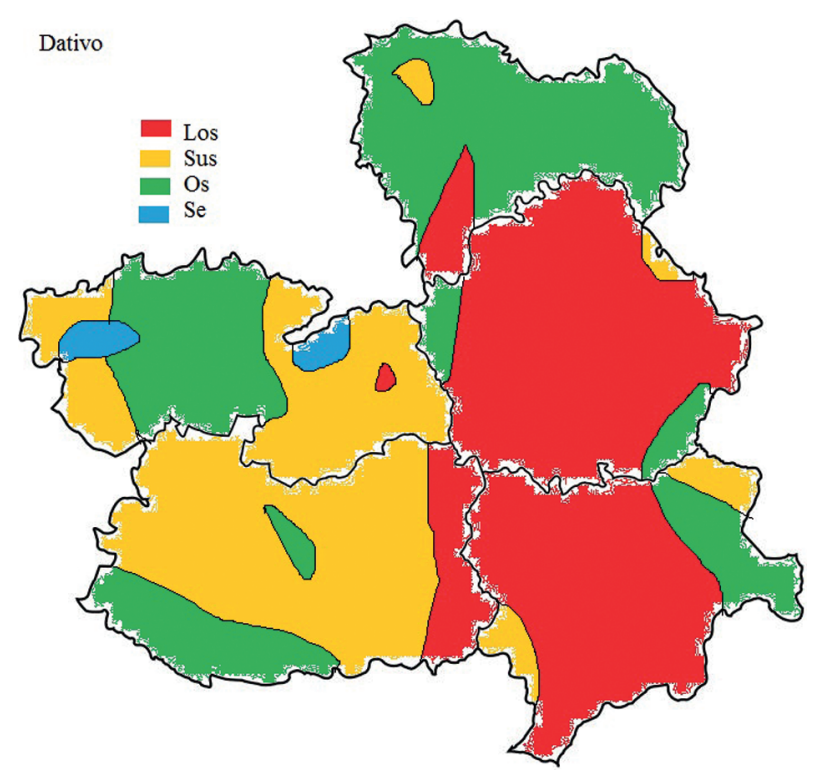

Mapa 8: Morfología del dativo.

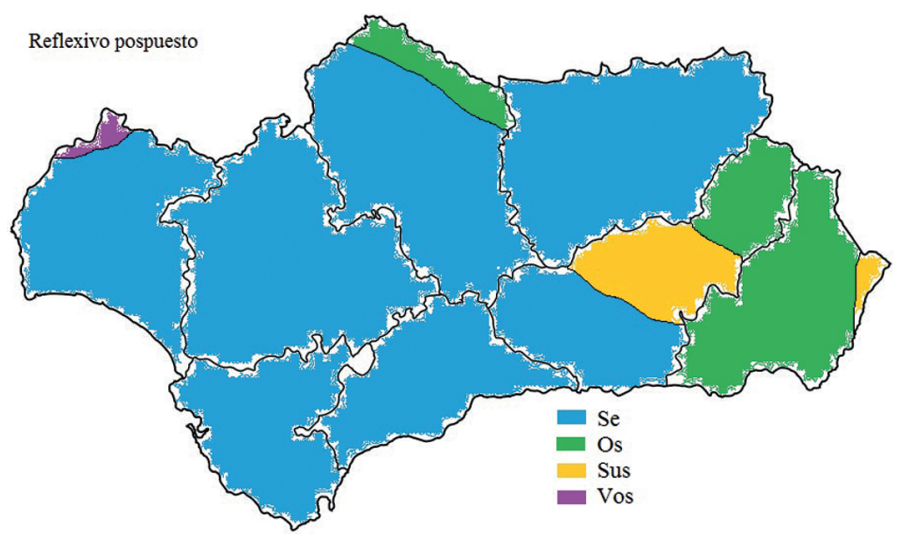

Mapa 9: Morfología del reflexivo pospuesto (II).

El mapa 9 muestra un reflexivo pospuesto, tras un imperativo que se ha producido como un infinitivo (arrodillar). La opción de se es casi unánime, aunque no se da en Almería, la mitad oriental de Granada y zonas del oeste onubense y norte de Córdoba. El estándar os impera en las demás zonas donde se no se manifiesta, salvo las ocurrencias de vos en el occidente y sus en Granada y parte de Almería. 


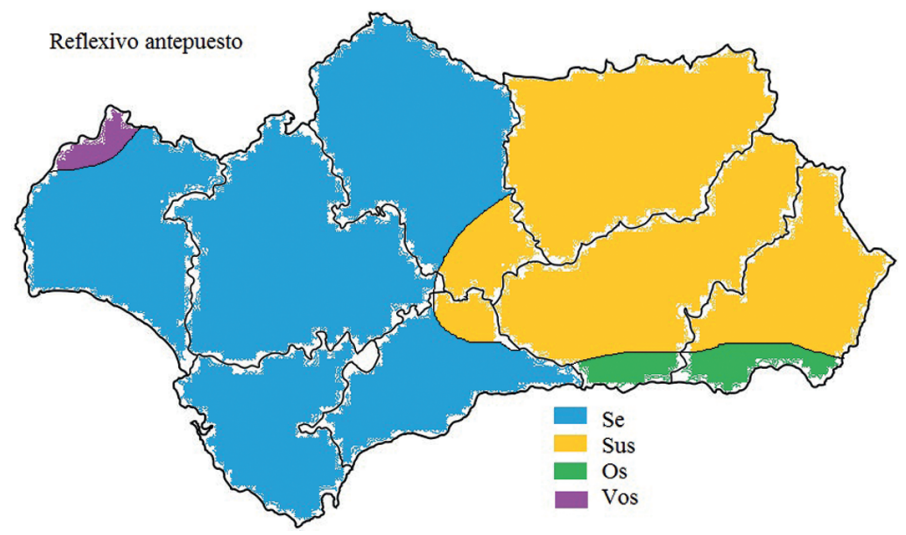

Mapa 10: Morfología del reflexivo antepuesto (IV).

El mapa 10 ilustra el reflexivo antepuesto, lo cual modifica la expresión del mismo en este contexto sintáctico. Por un lado, Andalucía oriental prefiere sus (excepto una franja meridional que opta por os); Andalucía occidental se decanta por se (salvo una zona occidental que sigue eligiendo vos).

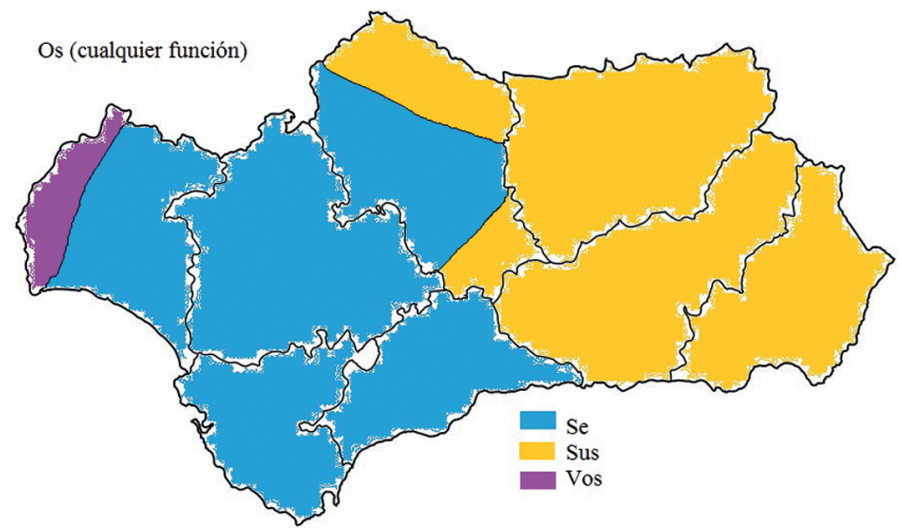

Mapa 11: Morfología de 2pl en ALEA.

A pesar de que el ALEA nos ofrezca dos mapas sobre la expresión de la 2pl como reflexivo en ambas posiciones sintácticas, el atlas añade una ilustración en la que recoge los alomorfos del clítico de 2pl para cualquier función sintáctica, literalmente para el reflexivo, el acusativo y el dativo (ya sea ético o un objeto indirecto canónico). El mapa 11 no solo contradice algunos datos de los anteriores (ya no existe os y sus se extiende levemente más en Córdoba y vos cubre todo el oeste de 
Huelva), sino que afirma que en Andalucía occidental el uso de se sirve para las siguientes frases (1-5).
(1) Se vais de viaje
(2) ¿Queréis irse de viaje?
(3) Se vi ayer
(4) Se di dinero
(5) Se coméis toda la tarta

De acuerdo con el mapa 11, los pronombres os, los, las, les habrían desaparecido favoreciendo la generalización de se para cualquier referencia de 2pl en cualquier función sintáctica. Repasemos a continuación los datos del ALEANR.

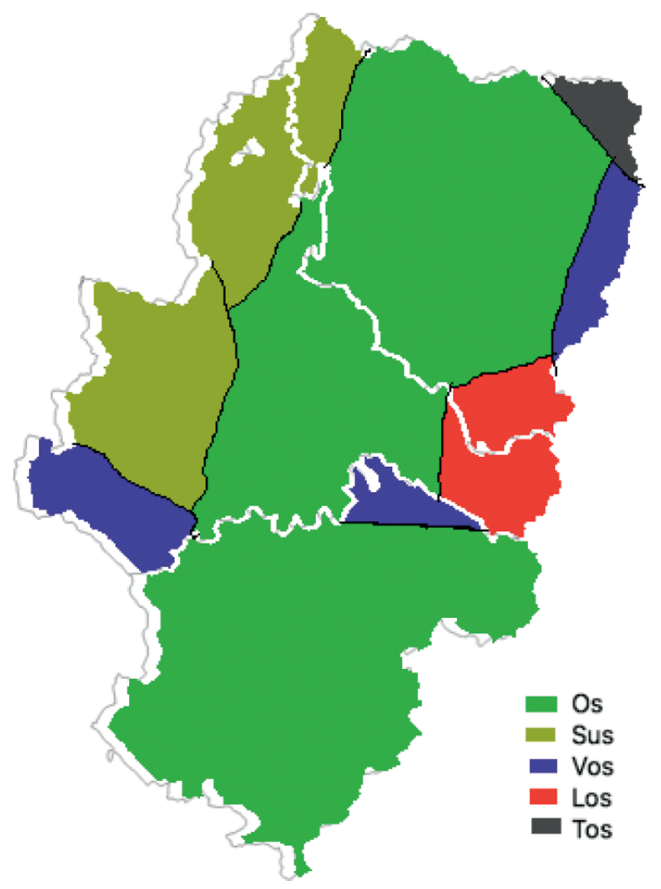

Mapa 12: Morfología de 2pl en ALEANR.

El mapa 12, sobre la pregunta os, en general, sin especificar la posición ni la función sintáctica, en el ALEANR ofrece la distribución que se presenta en Aragón (La Rioja y Navarra solo presentan registros de os a excepción algunos enclaves con sus). Advertimos una gran preponderancia de os en todo el territorio, seguido de sus en el oeste. De manera más dispersa hallamos soluciones de vos y un área 
muy concentrada de los y, en el noreste de Huesca, en zona pirenaica, la respuesta tos.

Por último, el ALECANT ofrece un gran uso de vos, salvo una zona del extremo occidental que presenta los y el estándar os, que surge en el extremo septentrional y en partes del centro-sur.

Pasemos por último a los datos que ofrece el COSER. Hay que advertir que la variante sus y los, al ser a la vez una forma de posesivo y de pronombre átono de 3 pl, así como un artículo, no han podido ser cartografiadas como una etiqueta aparte, ya que el programa aún no ofrece dicha posibilidad.

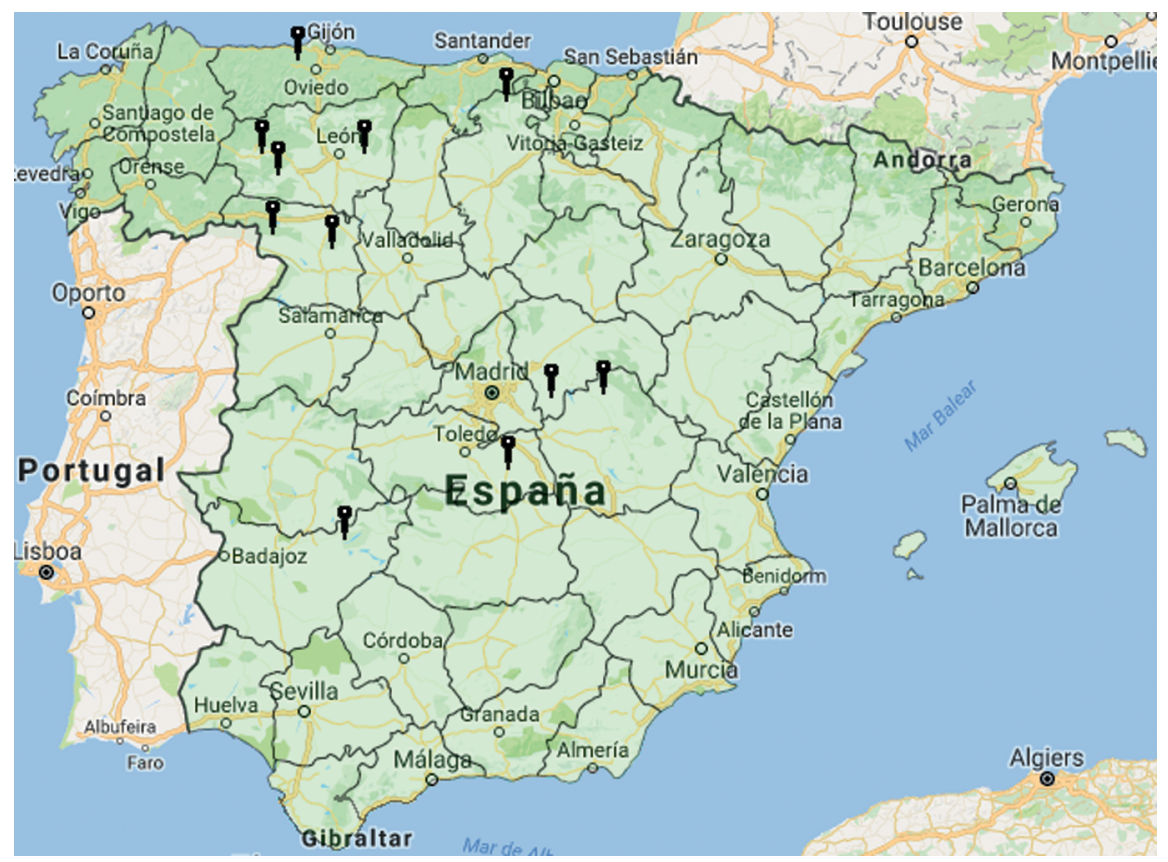

Mapa 13: Extensión de vos en la actualidad.

El problema que plantea el COSER por su metodología es la escasa posibilidad estadística de provocar la expresión de una 2pl por parte del informante. No podemos realizar una valoración cuantitativa sobre la producción de los alomorfos de 2pl ni tampoco basarla en función de su comportamiento sintáctico. Asimismo, no todas las grabaciones están subidas ni transcritas, por lo que nos conformaremos con los datos disponibles a día de hoy. Así las cosas, el uso de vos se ha documentado en zona occidental, si bien se observan ejemplos esporádicos en el centro peninsular. 


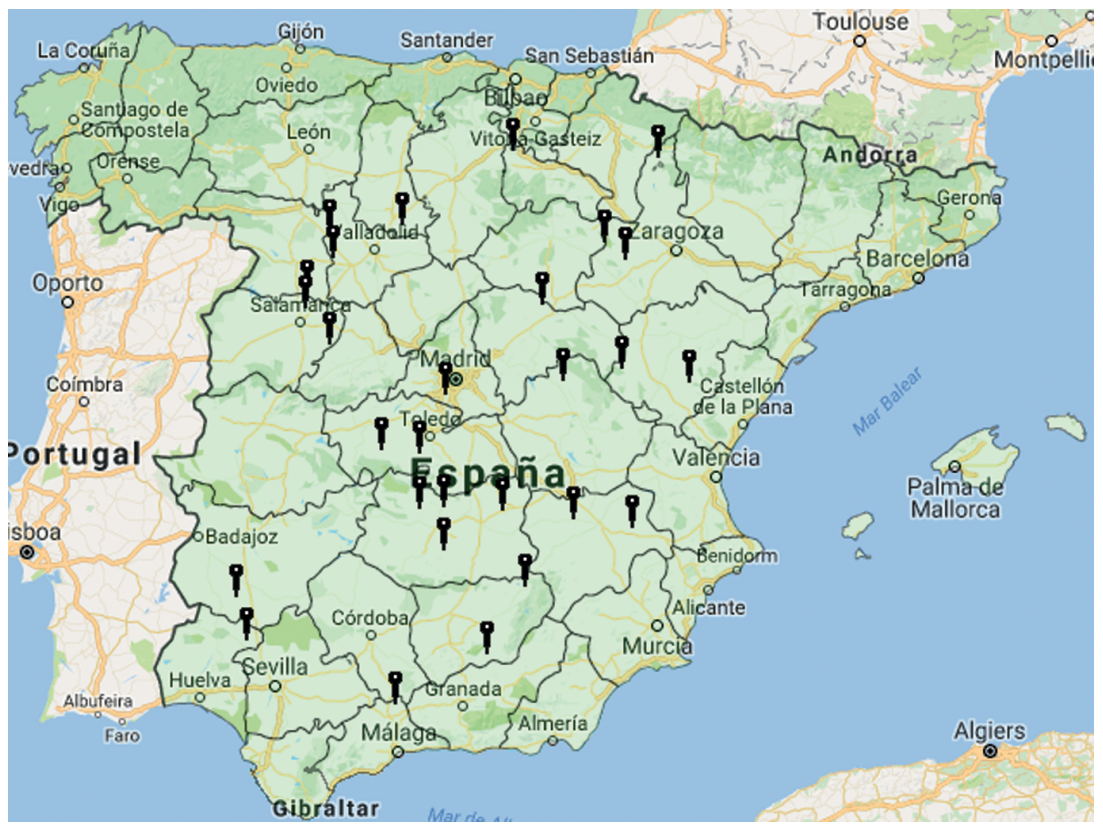

Mapa 14: Extensión de sus / sos en la actualidad.

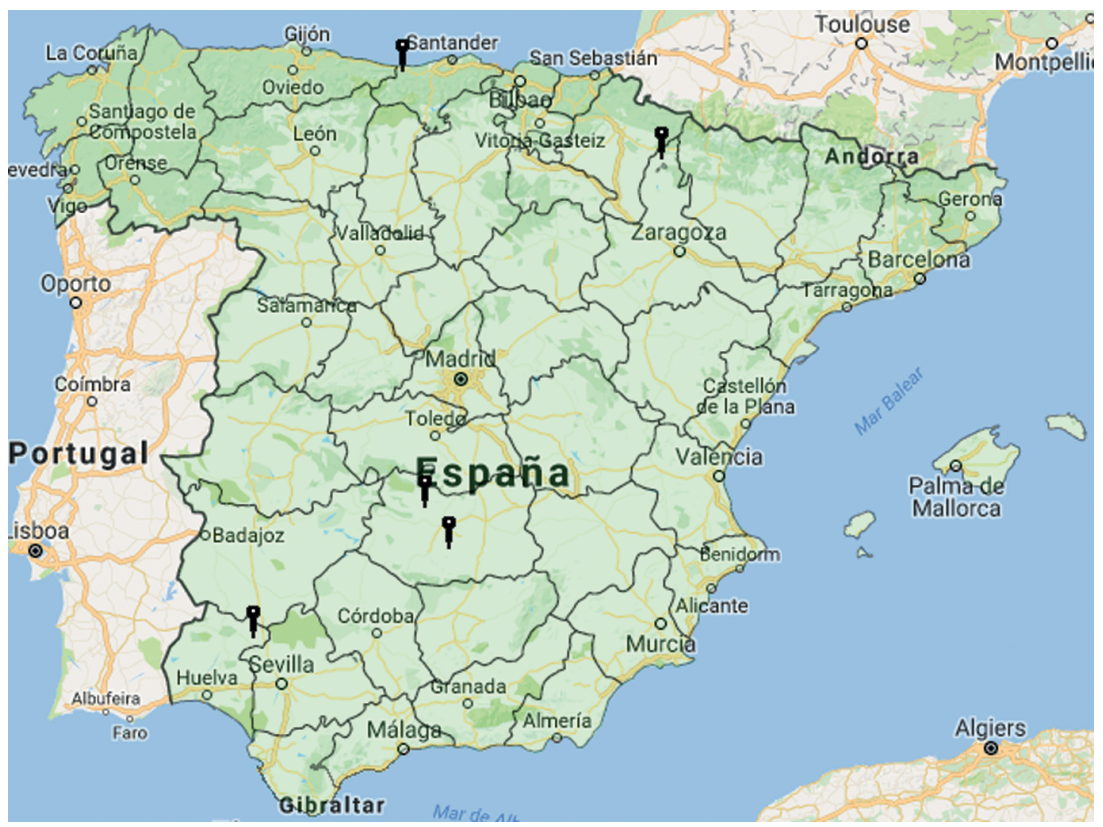

Mapa 15: Extensión de se os en la actualidad. 
El mapa 14 muestra mayor uso de sus / sos en el centro peninsular y, de manera más esporádica, en el sur.

El mapa 15 cartografía la posibilidad de encontrar la secuencia se os con referencia $2 \mathrm{pl}$ (se os dije [a vosotros]). No es en absoluto mayoritaria, pero concuerda con las investigaciones de Lara (2016) al respecto. En el apartado dedicado al análisis, ahondaremos en las razones lingüísticas de la casuística que hemos encontrado.

\section{Análisis}

A continuación, abordaremos un análisis teórico de los resultados, según los alomorfos atestiguados en los corpus y atlas que hemos manejado.

\subsection{El uso de vos}

La variante átona vos, que es la herencia latina directa de 2pl, es consistente en el occidente peninsular. A pesar de que su desgaste fonológico se documenta en el XII en posición enclítica tras formas no finitas o imperativos yusivos y se alarga hasta pasada la Edad Media (García/De Jonge/Niewenhuijsen/Lechner 1990; De Jonge/Nieuwenhuijsen 2006; Calderón Campos 2006), su permanencia es fuerte en la primera mitad del siglo XX incluso en contextos fonológicos donde la reducción a os estaría más condicionada. Los atlas posteriores nos muestran su escasa pervivencia en el extremo occidental de Huelva y de manera esporádica en otras zonas del español. El corpus dialectal COSER apenas da ocurrencias, si bien muchas se concentran en el occidente. Zamora Vicente (1970) siempre lo ha asociado con zona leonesa.

En el caso del portugués, vos se documenta en todo el centro-norte en cualquier contexto sintáctico de pronombre átono, pero es inexistente en el centro-sur como reflexivo. Además, a pesar de que esta área posee la norma de concordar en 2pl los objetos con referencia vocês, la expresión de esta en acusativo no se manifiesta en la totalidad de dicha región. Al contrario, la forma de 3pl os se extiende por una gran parte del sur portugués. De la misma manera, el catalán da muestras de la vigencia de vos en proclisis y de us en enclisis (aunque no en todo el conglomerado catalanoparlante). Otras zonas han generalizado, al menos en el reflexivo, la tercera persona (se), como ya han expuesto De Benito (2015) o Bonet i Alsina (1984). 


\subsection{El uso de los}

El empleo de los como único clítico de 2pl, independientemente de la función sintáctica, también sigue un patrón coherente a lo largo de la centuria pasada. Observamos su vigencia en el oriente peninsular y una zona aledaña al Guadalquivir en Sevilla y Cádiz. Ya lo documenta la NGLE, que lo circunscribe a Aragón, la Mancha y Murcia, y Enrique-Arias (2011) en el oriente peninsular. Su ocupación a cualquier función sintáctica átona ha provocado que pase también a la 1pl. Así, en ciertas zonas del oriente peninsular y el occidente andaluz, hallamos los con referencia nosotros (nosotros los reímos, a nosotros los ven), siempre y cuando esos mismos informantes incurran en el sincretismo en la 2pl (Lara/Díez del Corral 2015).

\subsection{El uso de tos}

Como apuntaban Zamora Vicente (1970) y Alvar/Pottier (1983), el surgimiento de tos se da en zona aragonesa pirenaica. Los datos nos demuestran que su distribución geográfica no ha cambiado en un siglo, ya que se sigue documentando en la misma área. El uso de la $t$ viene influenciado por la $2 \mathrm{sg}(t e)$, como en la $1 \mathrm{pl}$ el empleo de mos es una asimilación de la $m$ de me. Como Kayne (2003) apunta para el italiano de Milán, la $m$ ya no indica 1sg, sino primera persona, generalizándose al plural. Lo mismo puede aplicarse a la segunda persona en este caso; la $t$, por influencia de la 2sg, se incorpora a la 2pl, por lo que pasa a significar segunda persona, sin distinción de número gramatical.

\subsection{El uso de se y sus}

Sin duda alguna, los alomorfos vernáculos mayoritarios se corresponden con se y sus o la variante sos. Alvar/Pottier (1983) apuntan que las dos últimas son la consecuencia de la fusión de se más os, sin que se haya investigado más al respecto. Hemos observado que, efectivamente, el COSER da muestras de dicha secuencia sin fusionar y que tales ocurrencias pueden aparecer en distintos contextos sintácticos, como muestran (6-9).

(6) I1: Pues eso que siempre hay enchufe y los hijos de papá y mamá pues se comen a los pobres, [R-Ind] digo yo. ¿Vosotros no tenéis becas y cosas de esas así? ¿Y se os dan a todas iguales? Aer que ¿o no habéis oído comentarios que a unas les dan más que a otras, ¿no habís oído comentarios? 
E2: Pero eso depende de la situación económica, ¿no? No todo el mundo... COSER-1417-01 Porzuna (Ciudad Real)

(7) I: Llevaban una sayeja, como yo por ejemplo ahora mismo, y la bata vieja y ya está. Porque a lo mejor, no tenían, no sé, por lo que fuera. Yo eso no, no he carecido, aunque me las hiciera mi madre de un trapo viejo yo siempre he tenío. Pero había quien no las tenía y hoy mismo, pues no van | Mira, pues anda pa buscar ánde está eso, las bragas, la faja, el pantalón. ¿Es mentira lo que estoy diciendo? ¿A que sos estoy diciendo la verdad? Bueno, como se os está gustando lo que se sos digo. Que tengo que aviar de comer.

E: $\mathrm{Y}$, ¿el ajuar quién lo hacía?

COSER 1401-01 Aldea del Rey (Ciudad Real)

(8) E1: Y si quiere la, la invitamos a...

I1: No, no, no, muchas gracias.

E1: ¿A un café?

I1: Nada, no. Mu amable. Yo creo que se os habré servío de utilidá, ¿no?

E1: Sí, sí, mucho, y nos ha gustado mucho [RISAS] lo que nos...

I1: ¿Y esto ahora dónde, dónde lo escucha? [RISAS]

COSER 2122-01 Zufre (Huelva)

(9) I1: Y, y en los viajes también. [A-Nul] el otro día me preguntaban: «¿Tú no vas venir al tiempo libre?». Digo: «Yo sí». Dice: «¡Uy!, porque si tú no vienes [R-Ind], si tú no vienes, si tú no vienes no vamos nosotros tampoco».

E1: Por aquí están con lo de los chistes de Lepe.

I1: [RISAS] de Lepe. Se os voy a decí dónde está el estanco. Mira hijo, aquí, pa acá. [RVnt] Ande está ese | lo de Correos.

E1: Sí.

COSER 2122-01 Zufre (Huelva)

Los ejemplos (6-9) ilustran que la concatenación de se os puede ocurrir en reflexivo y dativo. No hemos hallado datos del acusativo, pero insistimos en que la metodología no favorece la producción de la 2pl.

Sin embargo, uno de los casos más llamativos a este respecto lo encontramos en el andaluz occidental. Lara (2016) ha descubierto en su análisis sobre el desplazamiento del pronombre vosotros por ustedes y las discordancias que induce el fenómeno que la $3 \mathrm{pl}$ se va imponiendo poco a poco sobre la $2 \mathrm{pl} \mathrm{y} \mathrm{que,}$ en un determinado momento, ambas coexisten. De esta manera, no solo se producen oraciones como la que plantea NGLE (ustedes vosotros sois hermanos), sino que llegan a explicitarse dos reflexivos seguidos de distinta persona (se os vais a callar) o dos objetos (se os doy las llaves; se os he visto paseando). Cada elemento alude a un pronombre concreto, pero lo interesante es hallar en los casos de objeto una 3pl que es claramente reflexiva en una función no reflexiva. En lugar de los os o les os, los hablantes optan por hacer análogo cualquier contexto sintáctico que se refiera a ustedes mediante el reflexivo se.

La relación de se como marca de objeto al ir acompañado de otro clítico (el se espurio) se ha achacado a diversos factores, uno de los cuales es el desplazamien- 
to de la lectura reflexiva a una de objeto. El asunto sigue siendo a día de hoy controvertido, pero lo más probable es que influyera un cúmulo de factores. Según Brakel (1979), Frago (1990) o García (2003b), la lengua medieval conocía las tres secuencias le lo, se lo y ge lo. Aunque la primera apenas se documenta (pero hay registros García 2003a, a pesar de la insistencia de Lapesa 1981, Cano 2004, Menéndez Pidal 2005 o Enrique-Arias 2011 de lo contrario), las dos últimas se diferenciaban en principio en el referente del objeto indirecto: se era reflexivo y ge de objeto de 3sg. La confusión de sibilantes que derivaría, entre otras cosas, en el seseo y ceceo actuales habría acercado fonéticamente las soluciones se lo y ge lo, hasta el punto de hacerse unívocas (Schmidely 1979). La expresión de se ya no solo aludía a la propia reflexividad, sino que podía asociarse con un referente que no era el propio hablante, sino una 3sg / 3pl ajena al sujeto.

En el caso del catalán, el uso de se en imperativos puede venir dado por la cercanía fonética entre us y se, lo cual habría favorecido también la nivelación en dicho contexto sintáctico (Perea 2011). Pero su expansión a cualquier lectura reflexiva independientemente de la persona (en plural) ya era vigente a principios del siglo pasado y aún se mantiene, a tenor de las investigaciones de Bonet i Alsina (1984) y De Benito (2015). La opción del portugués se explica por la nivelación de vocês para la 2pl, como ya se ha indicado a lo largo del trabajo.

El surgimiento de se en el andaluz tiene, no obstante, dos explicaciones distintas. Por un lado, observamos que los imperativos yusivos, al producirse como un infinitivo, fomentan la elección de la no persona o persona por defecto (la tercera), por lo que encontramos se pospuesto en una gran extensión del sur peninsular. Los casos de proclisis, no obstante, se concentran en Andalucía occidental (aunque hay escasos ejemplos en el oriente peninsular) por el hecho de contar con ustedes como único pronombre de 2pl (Lara 2012). La elección por tanto trata de ser congruente con la concordancia ( $3 \mathrm{pl}$ ) que alude a este tratamiento.

\subsection{Las funciones sintácticas y el sincretismo}

Aunque la base cuantitativa de los resultados que los atlas nos ofrecen no es la deseada, los mapas expuestos nos dan pistas sobre la importancia que la función sintáctica posee a la hora de construirse con un alomorfo u otro. Si nos atenemos a los mapas 1 y 2, el empleo de los es minoritario o casi inexistente si le precede la vibrante $r$ (beberlos este vaso de aguardiente) o el uso de se aumenta en infinitivos yusivos. Igualmente, frente al se reflexivo en Andalucía occidental, hallamos los de 2pl en la misma área, en consonancia con la situación oriental. Para el ALEA, se se produce también en Andalucía oriental en posición posverbal, frente al 
aumento de os en la misma ubicación si es preverbal (aunque luego entre en contradicción con el mapa 11).

En principio, es completamente verosímil que un informante sea capaz de alternar entre dos alomorfos de una manera más o menos caótica o los haya especializado para sendas funciones sintácticas. La metodología basada en recoger una sola respuesta por informante no puede dilucidar si esto ha sido así en la Península Ibérica a nivel dialectal, como tampoco nos lo dicen los corpus más modernos, debido a que la $2 \mathrm{pl}$ no surge con frecuencia en una conversación. Sin embargo, hay pruebas que apuntan a la importancia del contexto gramatical en la expresión de un fenómeno lingüístico dado.

Si nos mantenemos en el comportamiento de la 2pl, la misma aparición y posterior generalización de la forma compleja vosotros a costa de vós y nosotros a costa de nós se atuvo a la función sintáctica. Es decir, el desplazamiento de vós se inició en término de sintagma preposicional y, posteriormente, se universalizó al sujeto. El asentamiento de nosotros llegó por analogía de la forma de 2pl; dicho de otra manera, la evolución de las zonas complejas siguió este patrón: término de sintagma preposicional $2 \mathrm{pl}>$ sujeto $2 \mathrm{pl}>1 \mathrm{pl}$. Aún con los pronombres de $1 \mathrm{pl}$ y 2pl, Lara/Díez del Corral (2015) descubrieron que el empleo sincrético de los como clítico de $2 \mathrm{pl} \mathrm{y} 1 \mathrm{pl}$ recorría la jerarquía $2 \mathrm{pl}>1 \mathrm{pl}$, o sea, si aparecía para el referente nosotros, también lo hacía para vosotros. Igualmente las secuencias invertidas me se y te se siguen un patrón implicativo: el informante que produce me se lo hace con te se (Heap 2006).

Estos ejemplos del español en torno al carácter gradual del cambio lingüístico o la propagación o declive de un fenómeno pueden incluso extrapolarse al comportamiento de caso gramatical. Los clíticos de los que nos ocupamos se caracterizan por hacer referencia al sujeto de la frase, al objeto directo o al objeto indirecto. Ya Lara/Díez del Corral (2015) aludieron a la importancia del comportamiento gramatical del pronombre de $1 \mathrm{pl}$ para su expresión en mos, los o nos. Pero si hay un fenómeno lingüístico que claramente muestra la gradualidad del cambio de acuerdo con la función sintáctica es el investigado por Lara (en prensa) acerca de la generalización de ustedes como único pronombre 2pl en Andalucía occidental y de vocês en el portugués europeo. De acuerdo con el autor, la desaparición de vosotros y de vós en ambas variedades favoreciendo el uso único de ustedes y vocês (sintácticamente de $3 \mathrm{pl}$ ) no ha comportado la generalización de la concordancia en $3 p l$ en los elementos que dependen o se refieren a dichos pronombres. Las discordancias de persona pueden producirse entre sujeto y predicado (ustedes os vais), incluso entre reflexivo y verbo (se vais), con el objeto (a ustedes os vi ayer) y el posesivo (vuestros padres [de ustedes] han llegado). Según sus investigaciones, la $3 \mathrm{pl}$ se va extendiendo poco a poco siguiendo una jerarquía que se basa en la función sintáctica: sujeto > reflexivo > verbo > objeto 
directo > objeto indirecto > posesivo. Así, ya sea en portugués europeo o en andaluz occidental, la persona que produce una $3 \mathrm{pl}$ en un objeto indirecto con referencia ustedes / vocês, forzosamente concuerda en $3 \mathrm{pl}$ el verbo, el objeto directo, el reflexivo y el sujeto. El fenómeno lingüístico, por tanto, se supedita al contexto gramatical de cada elemento.

Esta jerarquía tampoco parece casual, ya que se atestigua también en la capacidad de formar oraciones pasivas o relativas. De acuerdo con Blake (2004), si una lengua es capaz de relativizar un objeto indirecto, lo hará también con uno directo y con el sujeto. El último elemento en relativizarse es el genitivo (función que suele ocupar el posesivo) y, de hecho, las lenguas parecen tener ciertas dificultades en mantener las oraciones relativas de genitivo, como atestigua Elvira (2015) a propósito de cuyo y otros nexos de otros idiomas. Pero la gradualidad o el contexto sintáctico no solo se reducen al ámbito de la morfosintaxis, sino que también se dan en la fonética. Estrada (2012) da cuenta de la caída de la /d/ intervocálica y final de palabra en español peninsular y advierte de la importancia del elemento fonético que precede o sucede y de la clase de palabra que pueda verse afectada. Así, si el elemento tiene una acentuación paroxítona, la caída sigue esta jerarquía: ádo > áda, édo, ódo, ído, ída > údo. En cambio, si es oxítona, la supresión se da recorriendo el siguiente continuum: adó > edó > udó.

Por tanto, la escasa o nula frecuencia de los pospuesto es un contexto fonético propicio para su no expresión, como lo fue la erosión de vos en español medieval. Asimismo, su expansión como clítico sincrético de 3pl, 2pl y 1pl es gradual y presenta una incidencia variable según se comporte como reflexivo, acusativo o dativo.

El caso de se nos lleva a otro desarrollo distinto. Recordemos que en las lenguas romances, el reflexivo y el objeto son sincréticos excepto en la 3sg y 3pl (Faltz 1985). Mientras me, te, nos, os pueden aludir a un reflexivo, acusativo o dativo, el uso de se se diferencia de lo, la, los, las, le, les en, precisamente, la función sintáctica. La extensión de se a otras personas está ampliamente documentada (De Benito 2015), pero siempre con una lectura reflexiva (se vamos, se vais); sin embargo, su generalización no reflexiva puede estar motivada por la secuencia se lo y la tendencia al sincretismo y a la pérdida de rasgos distintivos que padecen muchas lenguas desde un punto de vista tipológico (Velupillai 2013). Prueba de dicho sincretismo la hemos visto en los datos del ALEC-MAN, donde ciertos enclaves han producido tan solo se como objeto indirecto (se dan dinero [a vosotros]). Es cierto que tales ocurrencias son extremadamente minoritarias, pero reflejarían el estadio final de un proceso de cambio lingüístico referido al sincretismo, cuyas fases intermedias recaerían en la fusión de los dos pronombres (sos, sus) o la concatenación plena de ambos (se os). De hecho, Ronjat (1937) es el único autor que alude a esta posibilidad en las variedades provenzales del francés. De 
acuerdo con él, el se, tras extenderse sincréticamente a todo el paradigma reflexivo, ha saltado a lecturas no reflexivas y puede sustituir a nous o vous en dichas funciones; es más, el ejemplo que pone es el reproducido en (10).

(10) Apère - se [à nous]

Llamar.2sG.IMP. 3P.RFL. [a nosotros]

(lit. 'Llámase [a nosotros]')

Es sabido que el cambio lingüístico depende, entre otras muchas cosas, de la frecuencia (Chambers/Schilling-Estes 2013). La victoria o derrota de un nuevo fenómeno puede dirimirse en mucho tiempo, a lo largo del cual podemos atestiguar sus distintos estadios. El uso nuevo, que compite con el antiguo, no desplaza inmediatamente a este y, a menudo, ha de convivir con su rival. Así, la propuesta de crear una desinencia específica de 3sg en imperfecto de indicativo para diferenciarla de la 1sg convivió con el uso antiguo y nunca alcanzó una gran frecuencia, por lo que terminó sin consumarse (Elvira 2009). La misma aparición de las formas complejas vosotros y nosotros coexistió con vós y nós hasta que su frecuencia y la gradualidad a la que nos hemos referido precisamente sobre este fenómeno terminaron por desplazar las formas simples. Así las cosas, la producción de se os o su fusión en sus o sos no sería sino el paso intermedio en el que el uso nuevo (el sincretismo) convive con el uso tradicional y trata de sustituirlo. El cambio lingüístico es impredecible y tan verosímil es que el cambio se interrumpa en la fusión (sos, sus), como que se termine imponiéndose (como en los ejemplos del ALEC-MAN) o que la tendencia sincrética retroceda y no se consume. Independientemente del resultado, persistimos en la idea de que ambos elementos han de coexistir y que, a tenor de los datos, coexisten a día de hoy. Comparemos otros fenómenos cuya evolución nos muestra los distintos estadios a los que aludimos.

La conversión de un tópico en un sujeto es paradigmática a este respecto. Sintéticamente, un tópico es un elemento extraoracional (normalmente ubicado en la periferia izquierda), que informa del tema del que se habla y que, sintácticamente, ha de recuperarse mediante una anáfora ya dentro de la oración. No obstante, esta anáfora no tiene por qué concordar con el tópico (Givón 1975). La elevada frecuencia de colocar en posición de tópico el agente o el experimentante del verbo provoca que sean reinterpretados como sujetos (Hopper/Traugott 2003). Aun así, antes de que el tópico se torne completamente en sujeto, ha de coexistir con aquel al que quiere desplazar (Givón 1975), como lo muestran los ejemplos del italiano de (11-13).

(11) Lui, egli sa ogni cosa

Él él saber.3sg.prs. cada cosa

('Él lo sabe todo') 
(12) Lui e' sa ogni cosa

Él él saber.3sg.PRs. cada cosa ('Él lo sabe todo')

(13) Lui sa ogni cosa

Él saber.3sg.Prs. cada cosa

('Él lo sabe todo')

En (11-13), sacados de Ernst/Gleßgen/Schmitt/Schweickard (2008), observamos las tres fases que suelen experimentar. En (11), advertimos un elemento en posición topical, separado prosódicamente por una coma de la oración propiamente dicha. En esta, aparece una anáfora que hace referencia al tópico y que es el verdadero sujeto del verbo. La alta frecuencia de la construcción topical conlleva a la situación ejemplificada en (12). El tópico empieza a comportarse como un sujeto (ha desaparecido la coma, por lo que se inserta en la oración), pero aún mantiene elementos topicales, como la necesidad de seguir siendo referenciado por el sujeto al que quiere desplazar. En última instancia, el tópico es totalmente reanalizado como sujeto, la anáfora desaparece y la antigua forma de sujeto desaparece para dar paso al nuevo uso que se ha consumado (13).

Hemos argumentado que el cambio es paulatino e implicativo, por lo que podemos suponer que si se ha saltado a lecturas no reflexivas con referencia $2 \mathrm{pl}$, la $1 \mathrm{pl}$ ha podido también ceder a dicho fenómeno. Si hacemos una búsqueda de se como 1pl en lecturas no reflexivas, no hallamos datos en los atlas lingüísticos, pero el COSER nos proporciona un par de ejemplos que bien valen un análisis (14-15).

(14) I1: ¿Quién es, el [NP]?

I4: El [NP]. [HS:I1 Estas es que son estudiantas.] [NP] y el de la tía [NP], el hijo de la [NP]. [HS:I1 Ah, [NP].] Sí, están recogiendo todas las cosas antiguas de fotografías de cosas, de cosas, van a hacer un libro y no sé qué.

I3: $\mathrm{Y}$ a los, y a los viejos no se nos llevan.

I4: Oy, no por Dios, [NP], que no te se lleven. No, no, no, no, no, que no te se lleven no, que dures otros ochenta.

I3: Ya soy antiguo.

COSER 1607-02, Cardenete (Cuenca)

(15) E: Más del cerdo. A ver, en, la crianza tampoco.

E1: El pacharán.

E3: ¡Ah, sí! El pacharán, que se nos ha quedado... ¿Cómo..., con qué se hace?

I1: Pues,... el pacharán con anís y se le echa unos granos de canela... y un poco de azúcar. Y nada más, y..., y el anís.

E2: ¿Y cuánto tiempo hay que dejar el pacharán para que se fermente o algo así?

COSER 3222-01, Miranda de Arga (Navarra) 
Las ocurrencias de (14-15) muestran la concatenación de se nos para una lectura no reflexiva, de acusativo y dativo respectivamente. Aunque son solo dos, el corpus favorece la expresión de las terceras personas y la 1sg por el tipo de metodología, por lo que es posible que no hayamos hallado más por esta causa. Igualmente, si la $1 \mathrm{pl}$ sucumbe después de la 2pl, es plausible que apenas se documente aún la extensión de se no reflexivo a la 1pl. No obstante, los datos muestran que sí existe.

Por consiguiente, en consonancia con lo manifestado, el sincretismo de se a funciones no reflexivas comenzaría con la concatenación de ambas formas, seguida de su fusión en sos, sus y terminaría con su imposición como sucede en el ALEC-MAN. Desconocemos si el sincretismo se produjo primero en lecturas reflexivas y, posteriormente, saltó a las de objeto directo e indirecto, pero la gradualidad del cambio está demostrada, por lo que prevemos que haya sido así.

Independientemente de que el sincretismo se haga con se o los, observamos que es siempre la tercera persona, es decir, aquella por defecto, la que va copando los usos de las demás, siendo la primera persona la última en perder su marca distintiva (un hecho bastante difundido a nivel tipológico, Siewierska 2004). Más que una cuestión de coherencia a la hora de tener en la 2pl un clítico que siga la secuencia consonante + vocal + consonante, como en las demás personas, tal y como defiende Enrique-Arias (2011), el sincretismo se establece con base de 3pl. Ciertas zonas han optado por la forma de objeto incluso para lecturas reflexivas (los reímos, los reís), mientras que otras han escogido el camino inverso: la forma reflexiva sirve también para lecturas no reflexivas (se os veo). Esta última estrategia se ubica en el centro peninsular, aunque en un estadio intermedio, al que hemos denominado de fusión, expresado en sos, sus.

\section{Conclusiones}

La comparación de los distintos materiales al alcance que pueden cartografiar los alomorfos de 2pl a lo largo del siglo XX nos ha desvelado la cantidad de variantes existentes: os, sos, sus, los, tos, vos y se. Aunque la forma estándar apenas se documentaba en la primera mitad del siglo XX, los corpus posteriores dan cuenta de una mayor profusión a costa de otras soluciones dialectales. Aun así, observamos la conservación de tos en el entorno pirenaico de Aragón por influencia de tú; la permanencia de vos incluso en entornos fonéticos poco favorecedores en el oeste peninsular; el sincretismo en los en el oriente peninsular y zonas de Andalucía occidental; sos o sus por todo el centro peninsular, aunque su posición sintáctica limita la posibilidad de aparición; y, por último, el reflexivo se convertido en pronombre átono también de objeto en lecturas no reflexivas. 
El sincretismo atestiguado se manifiesta de dos maneras distintas. Ciertas regiones han generalizado la forma los a cualquier contexto sintáctico de 2pl (tras el cual cede la 1pl). Otras han optado por se para el mismo proceso, si bien su consumación tan solo se advierte en áreas castellano-manchegas; el resto del territorio aún se concentra en la fase de fusión de se más os: sos, sus. Este paso intermedio es habitual en el cambio lingüístico, ya que un uso nuevo trata de desplazar a otro y solo puede hacerlo de forma gradual. El estadio inicial, aunque lo hallamos con menor profusión, se materializa en la concatenación de se más os.

\section{Bibliografía}

ALEA = Alvar, Manuel/Llorente, Antonio/Salvador, Gregorio, Atlas lingüístico y etnográfico de Andalucía, Granada, Universidad de Granada, 1961-1965.

ALEANR = Alvar, Manuel, Atlas lingüístico y etnográfico de Aragón, Navarra y Rioja, Zaragoza, CSIC, 1979-1983.

ALECANT = Alvar, Manuel, Atlas lingüístico y etnográfico de Cantabria, Madrid, Arco Libros, 1995.

ALEC-MAN = García Mouton, Pilar/Moreno Fernández, Francisco, Atlas Lingüístico ( $y$ etnográfico) de Castilla-La Mancha, 1988-1994, <http://www.linguas.net/alecman/>.

ALPI = Heap, David, El Atlas lingüístico de la Península Ibérica (ALPI), Ontario, University of Western Ontario, 2003.

Alvar, Manuel/Pottier, Bernard, Morfología histórica del español, Madrid, Gredos, 1983.

Blake, Barry, Case, Cambridge, Cambridge University Press, 2004.

Bonet i Alsina, Maria Eulàlia, Morphology after Syntax. Pronominal Clitics in Romance, Barcelona, Universitat Autònoma de Barcelona, 1984.

Brakel, Arthur, The provenience and present status of Spanish «selo», Linguistics 17 (1979), 659670.

Brito, Ana Maria, et al., Gramática da língua portuguesa, Lisboa, Caminho, 72006.

Calderón Campos, Miguel, El desgaste pronominal y verbal de vos en la primera mitad del siglo xvi, in: Bustos Tovar, José Jesús de/Girón Alconchel, José Luis (edd.), Actas del VI Congreso Internacional de Historia de la Lengua Española, vol. 1, Madrid, Arco Libros, 2006, 557-568.

Cano, Rafael, Historia de la lengua española, Barcelona, Ariel, 2004.

Chambers, Jack/Schilling-Estes, Natalie, The Handbook of Language Variation and Change, Malden, Blackwell, 2013.

COSER = Fernández-Ordóñez, Inés, Corpus Oral y Sonoro del Español Rural (COSER), Madrid, Universidad Autónoma de Madrid, 1988-2016.

Cunha, Celso/Cintra, Luís Felipe Lindley, Nova gramática do português contemporâneo, Lisboa, João Sá da Costa, 1992.

De Benito, Carlota, «Pero se escondiamos como las ratas»: syncretism in the reflexive paradigm in Spanish and Catalan, Isogloss 1 (2015), 95-127.

De Jonge, Bob/Nieuwenhuijsen, Dorien, Formación del paradigma pronominal de las formas de tratamiento, in: Company Company, Concepción (ed.), Sintaxis histórica de la lengua española. Segunda parte: la frase nominal, vol. 2, México DF, UNAM, 2006, 1593-1672. 
Elvira, Javier, Evolución lingüística y cambio sintáctico, Bern, Lang, 2009.

Elvira, Javier, Lingüística histórica y cambio gramatical, Madrid, Síntesis, 2015.

Enrique-Arias, Andrés, El sincretismo de personal en el plural de los pronombres clíticos del español (os nos y los), in: Stark, Elisabeth/Pomino, Natascha (edd.), El sincretismo en la gramática del español, actas de la sección del mismo título en el XVII Congreso de la Asociación Alemana de Hispanistas, Madrid/Frankfurt, Iberoamericana/Vervuert, 2011, 99-118.

Ernst, Gerhard/Gleßgen, Martin-Dietrich/Schmitt, Christian/Schweickard, Wolfgang (edd.), Romanische Sprachgeschichte, vol. 3, Berlin/New York, Mouton de Gruyter, 2008.

Estrada, Ana, The loss of intervocalic and final / d/ in the Iberian Peninsula, Dialectologia Special Issue 3 (2012), 7-22.

Faltz, Leonard, Reflexivization. A Study in Universal Syntax, New York, Garland, 1985.

Fernández-Ordóñez, Inés, New methods for the study of grammatical variation and the Audible Corpus of Spoken Rural Spanish, in: Aurrekoetxea, Gotzon/Ormaetxea, José Luis (edd.), Tools for Linguistic Variation, Bilbao, UPV, 2010, 119-130.

Frago, Juan Antonio, El cambio de «ge lo» a «se lo» en testimonios andaluces, Anuario de Lingüística Hispánica 6 (1990), 217-224.

García, Erica, La apócope de «gelo» y el valor de «se» en español moderno, Neuphilologische Mitteilungen 104:1 (2003), 11-46 (= 2003a).

García, Erica, Modern Spanish spurious «se»: a genuine case of pseudo analysis, Linguistics 41 (2003), 989-1040 (= 2003b).

García, Erica/De Jonge, Robert/Niewenhuijsen, Dorien/Lechner, Carlos, «(V)os-(otros)»: ¿dos y el mismo cambio?, Nueva revista de filología hispánica 37:1 (1990), 63-132.

Givón, Talmy, Topic, pronoun and grammatical agreement, in: Ni, Charles (ed.), Topic and Subject, New York, Academic Press, 1975, 149-188.

Heap, David, Secuencias «invertidas» de clíticos: un cambio (i?) en tiempo real, in: Bustos Tovar, José Jesús de/Girón Alconchel, José Luis (edd.), Actas del VI Congreso Internacional de Historia de la Lengua Española, Madrid, Arco Libros, 2006, 785-798.

Hopper, Paul/Traugott, Elizabeth Closs, Grammaticalization, Cambridge, Cambridge University Press, 2003.

Kayne, Richard, Person morphemes and reflexives in Italian, French and related languages, in: Tortora, Christina (ed.), The Syntax of Italian Dialects, Oxford, Oxford University Press, 2003, 102-136.

Lapesa, Rafael, Historia de la lengua española, Madrid, Gredos, 1981.

Lara, Víctor, «Ustedes» instead of «vosotros» and «vocês» instead of «vós»: an analysis through the Linguistic Atlas of the Iberian Peninsula (ALPI), Dialectologia Special Issue 3 (2012), 57-93.

Lara, Víctor, When agreement is for covert and not for overt: the case of «ustedes» plus second person plural inflections in Peninsular Spanish, Isogloss 2:2 (2016), 95-111.

Lara, Víctor, Relaciones de caso y extensión de la concordancia en el español peninsular y el portugués europeo, Revista de Filología Española, en prensa.

Lara, Víctor/Díez del Corral, Elena, Los clíticos de primera persona del plural en las lenguas peninsulares: una visión dialectal, Zeitschrift für romanische Philologie 131 (2015), 950-977.

Menéndez Pidal, Ramón, Historia de la lengua española, Madrid, CSIC/Fundación Menéndez Pidal, 2005.

NGLE = Real Academia Española/Asociación de Academias de la Lengua Española, Nueva gramática de la lengua española, Madrid, Espasa, 2009. 
Penny, Ralph, Variación y cambio en español, Madrid, Gredos, 2004.

Perea, Maria Pilar, Els imperatius en contacte amb els enclítics pronominals, in: Lloret, Maria Rosa/Pons, Claudia (edd.), Noves aproximacions a la fonologia i morfologia del català, Alicante, IIFV, 2011, 427-457.

Ronjat, Jules, Grammaire historique des parlers provençaux modernes, Montpellier, Société des Langues Romanes, 1937.

Sanchís Guarner, Manuel, et al., El Atlas lingüístico de la Península Ibérica (ALPI). Trabajos, problemas y métodos, in: Actas del IX Congreso Internacional de Lingüística Románica, Lisboa, Centro de Estudos Filológicos, 1962, 113-120.

Schmidely, Jack, De «gelo» à «selo», Cahiers de Linguistique Hispanique Médiévale 4 (1979), 63-70.

Siewierska, Anna, Person, Cambridge, Cambridge University Press, 2004.

Velupillai, Viveka, An Introduction to Linguistic Typology, Amsterdam, Benjamins, 2013.

Wheeler, Max/Yates, Alan/Dols, Nicolau, Catalan. A Comprehensive Grammar, London, Routledge, 1999.

Zamora Vicente, Alonso, Dialectología española, Madrid, Gredos, 1970. 